\title{
Socio-Individual Prerequisites of Energy Transition in Iran: Investigating Public Acceptance of Solar Panel Technology in Rural Areas
}

\author{
SARA KARIMZADEH ${ }^{1 *}$ AND Eva KašPAROVÁ ${ }^{2}$ \\ ${ }^{1}$ School of Humanities, Education and Social Sciences, Örebro University, Örebro, Sweden \\ ${ }^{2}$ Department of Managerial Psychology and Sociology, Faculty of Business Administration, \\ Prague University of Economics and Business, Czech Republic
}

\begin{abstract}
Iran has inordinate natural capacity to benefit from solar energy all year. Interim plans by the Iranian government have been implemented to develop energy transition in rural areas, however, the outcomes have not been promising so far. This research seeks to address the question of what factors influence villagers' tendency towards solar panel acceptance for domestic usage. To answer the question, a survey was conducted among residents who had not installed the new technology in the survey time. A model based on the modified framework of the Technology Acceptance Model for energy transition was developed and data was collected from the northern part of Iran-Mazandaran province. The data revealed that through the mediating role of attitude, the strongest effect on adoption intention relates to perceived usefulness. The paper discusses why solar energy technology is not welcomed in the studied community. The findings contribute to increase our knowledge about underlying factors on the development of public adoption of renewable energies in a developing country.
\end{abstract}

Keywords: energy transition, solar panel, Technology Acceptance Model (TAM), Iran

\section{INTRODUCTION}

Although Iran has a high natural potential to generate its' required electricity from renewable resources (RE) and the first steps to enter them into the energy market were taken in 1994, they still have an insignificant role in the country's energy sector [1-3]. Insufficient policies, unbridled consumption as well as unsustainable process of energy production have made the country the third-largest gas consumer globally. However, there has been a yearly increase $7 \%$, which will soon make it the largest gas consumer [4]. Over-reliance on non-renewable energy resources and excessive use of conventional energy has put extra pressure on the country's natural sources. To alleviate these consequences, eventually, in the 4th five-year national development

\footnotetext{
${ }^{*}$ Corresponding author: Sara Karimzadeh, Department of Sociology, Örebro University, 70182 Örebro, Sweden. Email: sara.karimzadeh@oru.se

Received: 9 Oct 2021 Accepted: 16 Nov 2021 Published: 23 Nov 2021

Journal of Asian Energy Studies (2021), Vol 5, 42-57, doi:10.24112/jaes.050004
} 
plan (2005-2010), the Iranian government obliged the Minister of Energy to increase the share of renewables and clean power plants to at least 5\% of the country's capacity until the end of 2021. This decision was made due to the number of sunny days and the width of the country as well. Iran ranks in the 7th place globally in terms of renewable resources [5] and its average capacity of power generation is 2.5 times greater than European countries [6]. However, without enjoying this natural blessing, the country is the world's 23rd largest economy and is responsible for $1.80 \%$ of $\mathrm{CO}_{2}$ emissions and is ranked 7th globally [7].

To meet the international commitments made, such as United Nations Framework Convention on Climate Change (UNFCCC) in the Paris Agreement and Kyoto Protocol to reduce the emission rate up to $12 \%$ by 2030, in recent 10 years, the government has apparently obliged to invest in renewable and sustainable energy sources [7]. Policies were developed to ask the private sector to develop solar plans. Even foreign countries like Germany and international companies (a German-Spanish investor) were invited to come to Iran and draw a contract with SUNA ${ }^{1}$ [8]. How successful has this targeting been so far? It seems by producing less than $3 \%$ of the required energy from renewable energy resources like solar and wind, this policy has not acted so promising in its objectives.

Besides some aforementioned policies and some other strategies including feed-in-tariff strategy, contributing to localizing solar technology, and encouraging research centers to expand REs projects, one interim strategy to approach the set objectives is providing access to renewable energy for remote and undeveloped villages [3] and encouraging householders to get involved in green energy programs. Employing solar energy in rural areas has become government priority in recent years due to four reasons: (i) the high price of the conventional fuels for villagers in comparison to their income; (ii) high cost of fuel transportation to remote areas; (iii) encouraging rural inhabitants to become independent energy producers; and/or (iv) connecting remote areas to the national power grid [5]. Construction of solar energy plants has been on the agenda in districts of several big provinces, such as Shiraz, Semnan, Yazd, and Tehran and at the same time, SATBA's experts ${ }^{2}$ are attempting to extend the utilization of solar panels in rural parts of Mazandaran, Kerman and Zanjan cities [9]. Mazandaran province is one of the pilot locations of the newest Iranian governments' RE plans due to its high density of rural population. The government has started to install solar panels on rooftops of administrative buildings from schools to hospitals, especially in rural areas of this district. All these efforts were employed to encourage householders and individuals to embrace the new technology. Academic researchers started to evaluate the employed policies, which revealed several insignificant factors that influence RE's development. Most of the previous research evolved around identifying technical or demographical factors and the study of the impact of socio-cultural factors was not in vogue; thus, our knowledge about the issue and its necessities are in the early stages.

In a recent study, Karimzadeh and Salehi [10] argue that due to the weaknesses in communication channels, lack of appropriate energy culture and unprepared social structure, achieving the objectives of solar panel development is a premature target in the current context. Some other obstacles for the development of REs that Aien and Mahdavi [8] mention are complicated bureaucracy for power plant construction, relatively inconsistent economic status of the country, energy subsidies, economic sanctions and problems for technology transfer. Rezaee et al. [2] revealed that international sanctions, focusing on the development of conventional energies and the absence of proper environmental policies are some of the most effective impediments in the

\footnotetext{
${ }^{1}$ Renewable Energy Organization of Iran (SUNA) was merged with the Energy Efficiency Organization of Iran (SABA) to create the Renewable Energy and Energy Efficiency Organization (SATBA).

${ }^{2}$ Renewable Energy and Energy Efficiency Organization/ SATBA (2020) Annual Report on Renewable Energy and Employment-2018; SATBA: Tehran, Iran.
} 
development of REs in Iran. Rezaie and Ghofranfarid [11] identified four variables of perceived behavioral control, moral norms, relative advantage and awareness that have a positive and significant correlation with intention adoption. Implementing some innovative policies, such as allocating more incentive mechanisms for new technologies, mitigating political and regulatory risks, raising public awareness, as well as more investment in $R \& D$, are comprehensive suggestions that Afsharzadeh et al. [5] provided for the better development of the RE in developing countries like Iran. Nejat et al. [3] argued that obstacles, such as insufficient budgets, lack of human resources prowess and technical knowledge, as well as insufficient administrative and supervisory structure, are some main reasons for the failure of predicted objectives in the national development plans. Similarly, Ardehali [12] and Hemmati [6] mentioned the importance of the structural feasibility of the country in the development of this technology. Other studies declare that positive effective variables on the acceptance of new energy resources and technologies include literacy level, cost of gas and electricity for home, information and livestock unit [13], moral norms, attitudes and perceived behavioral control [14], knowledge of the issue [15] and education, age, and income [16].

By keeping these factors in mind and in the framework of the Technology Acceptance Model (TAM), this study aims to answer the following question: What factors influence attitudes and adoption intentions of villagers toward solar panels acceptance and non-acceptance? To answer this research question, in addition to the established constructs of the original TAM, three variables of trust in developers, cost and knowledge which extended from TAM research, have been added in the research model. The research model has tried to develop local factors that provide information regarding individuals' attitudes and adoption intention in a developing country. The findings contribute to the energy transition literature by increasing our knowledge about underlying factors regarding the development of public adoption of renewable energies in a developing country.

The rest of the paper is structured as follows: Section 2 includes literature reviews and the research model. Section 3 describes the method used and is followed by measures in Section 4 . Results are presented in Section 5 and a general discussion in Section 6. Conclusions and potential explanations are discussed in Section 7.

\section{Literature Review and Research Model}

\subsection{User Acceptance of New Energy Forms}

The modern approaches regarding the energy issue refuse to apply just a technical point of view. In recent decades, social scientists aimed to identify the social barriers that hamper individuals having conservative behaviors [17]. Wustenhagen, Wolsink and Burer [18], as well as Mallett [19] believed that although social acceptance is a determinant factor in the adoption of renewable energy resources, it has not been adequately discussed. New energy adoption literature such as [19-22] indicate that there is a broad range of social, cultural, economic, and demographic factors that may influence energy behavior. Recently, Liu et al. [21] argued that one of the key factors to develop green energy is public acceptability. Data revealed it can be influenced by factors, such as REs cost, income of adopters, trust/mistrust, information on new technologies, and planning problems [23,24]. Being acquainted with the new technology [25], price [26], and governmental support, such as subsidies for new energy sources and modern technologies [27] and high density of residential new technology in a region [28] are significant variables that influence new energies acceptability. Moreover, some similar studies have been carried out in neighboring countries of Iran. For instance, in Mirza et al. research in Pakistan, the main barriers to the development of REs are classified into information and social barriers as well as technological, market-related, fiscal and financial, institutional and regulatory barriers [29]. Another similar 
study has been conducted in Turkey by Nalan and Nuri [30] and a similar result has been obtained. In their study, the authors argued that economic factors, financial problems, technology costs, and technological deficiencies broadly influence the development of REs in the country.

One of the latest studies on social acceptance of renewable energy is related to a contingent valuation investigation in Western Greece. Paravantis et al. [24] revealed that younger, better educated, and richer respondents have a more positive attitude toward renewable energy. Their result showed age, family size, and knowledge on renewable energy were the variables strongly associated with actual electricity payments, whereas age, income, and attitude towards the future role, impacts, and obstacles to renewable energy projects were more strongly associated with a willingness-to-pay. Korcaj et al. [31] conducted a study to explore the motives of homeowners relevant to photovoltaic system purchase intention. Their results showed that the basic willingness to adopt a PV system was high, whereas willingness to pay was low. They illustrated that the attitude toward PV systems was mainly based on the aspirations of social status and financial gains, whereas costs, efforts, and risks associated with PV systems were detrimental to attitude.

\subsection{Technology Acceptance Model and Research Hypothesis}

Openness to new technology plays a remarkable role in the development of said technology. Davis et al. [32] originally presented the Technology Acceptance Model (TAM) based on the Theory of Reasoned Action (TRA) and the Theory of Planned Behavior (TPB) to understand the willingness of people toward new technology [33]. These theories are usually applied to predict consumers' attitudes, intentions, and actual behavior regarding a new product or technology. Two factors that have significant roles in the TAM model are perceived usefulness (PU) and perceived ease of use (PEOU) [32]. However, these variables have an interrelationship as well and Venkatesh and Davis [34] argue that PEOU can positively influence PU. Many researchers have developed the adjusted forms of the model and research background shows that the model has frequently been applied in renewable energy studies [35,36]. From 1989 onward, TAM has been applied in many green energy technology studies and the examination of external variables' effects on internal acceptance of new technologies [35].

In this study, the model is being used in the Iranian context where the feasibility of solar energy is high but social acceptance of renewable energy is dramatically low. According to Kardooni et al. [36], individuals' attitude toward energy is influenced by cost, knowledge, perceived ease of use (PEOU), and perceived usefulness (PU). Perceived ease of use (PEOU) refers to the degree to which a person believes that equipment would be easy to use and perceived usefulness (PU) is defined as the extent to which user belief can get satisfaction or benefit from using specific equipment [33]. The research model of the present study [Figure 1] used the original constructs of TAM and evaluates individuals' adoption intention toward applying solar panels for domestic usage. In addition to original constructs of TAM including PU and PEOU, attitude and adoption intention, the research model of this study has three extra constructs-trust in developers. Trust is an important factor in the social acceptance of energy transition and without relying on developers, energy companies, governments and NGOs, the development of a sustainable energy transition cannot be feasible [21,37,38]. Similarly, Stern and Dietz [39] emphasize the functions of organizations, firms, and industries to encourage individuals to incline to sustainable energy behaviors. This factor can affect decisions through attitudes $[40,41]$. Trust in developers of the energy transition, in terms of technologically and regulatory creates either through a social sphere or pioneering users of the new technology. Therefore, in the modified model of the research, it is hypothesized that trust in developers can also affect inhabitants' adaption intention through their attitudes. Furthermore, according to previous studies $[42,43]$, which declared a significant 
relationship between personal factors and willingness to shift to a new source of energy, a set of demographic variables have been added to hypotheses. Cost and knowledge, are two other constructs that have been placed in the research model to localize the research and model. Attitude toward solar panel acceptability is determined by the variables of knowledge of solar energy, trust in developers, PEOU, PU, the cost of rooftop solar panels, and demographic factors. Figure 1 depicts the research model and the possible relationship between constructs.

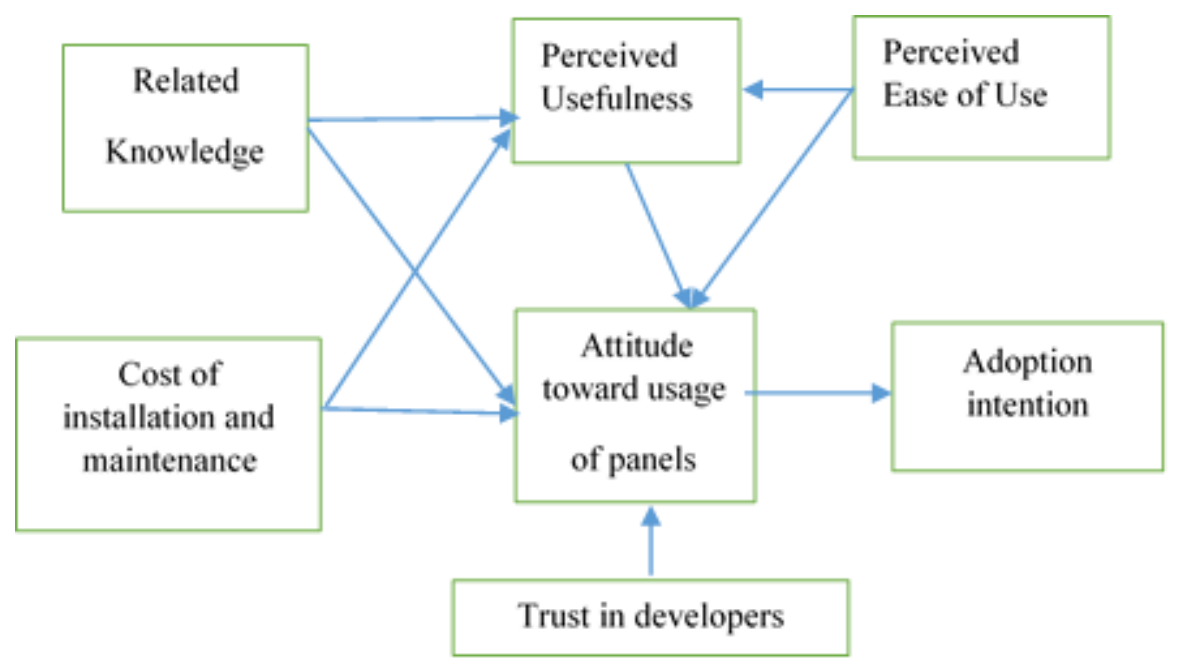

Figure 1: The theoretical model of research

Inspired by TAM, This research seeks to address the question of what factors determine inhabitants' tendency toward solar panel technology for domestic usage in the Iranian context. According to the model of the study, ten hypotheses were extracted as follows.

- H1: It is supposed that demographic variables (such as age, gender, income, and education) have a significant effect on individuals' attitudes toward solar panel installation.

- H2: Perceived usefulness positively influences households' attitude toward solar panel usage.

- H3: Perceived ease of use positively influences households' attitude toward solar panel usage.

- H4: Costs of solar panel installation can negatively affect households' attitudes.

- H5: Trust in developers positively influences households' attitudes toward usage of it.

- H6: Households' knowledge has a positive relationship with their attitudes toward solar panels.

- H7: Perceived ease of use positively influences perceived usefulness of solar panels.

- H8: Related knowledge has a positive relationship with perceived usefulness of solar panel usage.

- H9: Cost of solar panels usage has a negative influence on perceived usefulness of solar panel usage.

- H10: Households' attitudes influence their adoption intention.

\section{METHOD}

To achieve the goals of the study, a quantitative study was designed. A structured questionnaire based on the current knowledge and existing models was developed for the local context. The 
questionnaire consisted of two parts: 1) main questions, and 2) demographic information. To determine demographic characteristics, nominal scales and for measuring the main variables, the five-point Likert scale was used. The main part of the questionnaire was developed based on $[31,33,36,44,45]$. For model designing, four constructs of PU, PEOU, and adoption intention were adapted from TAM and three constructs of related knowledge, trust in developers, and cost were added to develop a modified model based on literature review and local context. It is worth noting that items were used to measure individuals' attitudes regarding the role of the government in the expansion of solar panels for domestic use. Table 1 gives more information about constructs.

Table 1: Validity and reliability coefficients for constructs

\begin{tabular}{lcccc}
\hline Constructs & Number of items & Alpha coefficient & \multicolumn{2}{c}{ Exploratory factor analysis } \\
& & & KMO & Barlett's sig \\
\hline Adoption intention & 4 & 0.814 & 0.776 & 0.000 \\
Attitude toward usage & 5 & 0.707 & 0.753 & 0.000 \\
Perceived usefulness & 4 & 0.747 & 0.725 & 0.000 \\
Perceived ease of use & 4 & 0.755 & 0.734 & 0.000 \\
Cost of solar panel & 3 & 0.805 & 0.703 & 0.000 \\
Knowledge & 2 & 0.685 & 0.699 & 0.000 \\
Trust in developers & 3 & 0.839 & 0.701 & 0.000
\end{tabular}

Note: A reliability coefficient of (Cronbach's Alpha) 70\% or higher is considered "acceptable" in most social science research [46].

Data was collected from residents who were family breadwinners and had not, at the time of the study, installed solar panels to generate their households' electricity needs. There were several justifications for data collecting from northern villages. Around $25 \%$ of the population are settled in rural areas and their extensive unemployment rate can robust the importance of solar panel installation as a source of side income. Moreover, based on national reports, improving energy structure in Iran creates 31,271 jobs for Iranians, and villagers can have a significant part in this opportunity (SATBA 2020). The second one was related to the small benefit-taking of fossil fuels in villages in Iran. It was believed that this deprivation may lead to more interest in solar panel adoption.

Given the scattering of the rural population in this area, a quantitative research design was followed using a non-probability sampling method. Initially, a pilot test consisting of 50 samples was conducted among academic professionals and 30 samples among end-users to establish the content validity of the items and to detect unclear items and any deficiencies of the questionnaire. The final respondents were the residents of rural areas of Mazandaran province situated in the northern part of Iran with a population of 1,576,116 permanent residents according to the 2016 national census. The survey was conducted from September to December 2019 and a total number of 493 volunteer respondents who were meeting the aforementioned sampling criteria completed the survey. Questionnaires were distributed through research group members and respondents completed them personally. Student-helpers were recruited to aid the research team in collecting the data. All questionnaires were filled up by contacting the respondents at their house or work place. Overall, data was collected from 19 villages that in the Iranian administrative division terminology are called Dehestan. In some limited cases where respondents felt some difficulties in filling up the forms, the questions were read aloud by the interviewer. After collecting all the responses, 31 questionnaires were deleted as unanswered ones. Thus, 462 were used for analysis. 
Statistical analysis of the data was conducted using IBM SPSS Amos 22 and results are surmised in the following section.

\section{Measures}

Data analysis shows that the majority of respondents (52.2\%) have no serious intention to move toward solar panel usage in the domestic area. $28.4 \%$ mentioned that they would do so soon. $60 \%$ of respondents mentioned that this is a very useful technology and more than $56 \%$ mentioned that they are not sure whether it is easy to apply or not. Meanwhile, around $12 \%$ believed that this is not easy for them to apply roof solar panel technology. Among respondents, more than $41 \%$ expressed that solar panel technology is expensive for them and $9 \%$ expressed affordability of buying the technology. When it comes to trust, around 59\% do not trust solar panel developers. $42.9 \%$ of their responses to the question "Do you think solar panel sellers are reliable?" was "I don't know". Regarding trust in solar panels' advertisers and governmental officials who invite people to apply solar panels, it was revealed that $48.7 \%$ and $42 \%$, respectively had no idea about these items. The responses showed that $51 \%$ of participants have a favorable attitude about solar panels conditioned the technology receives governmental financial support. Respondents' Knowledge about the positive effects of solar panel usage on the mitigation of climate change and the emission of greenhouse gases was reported low. Of two questions about the positive impacts of solar panel technology on the decreasing of the planet's temperature and emission of greenhouse gases $42.4 \%$ and $40.7 \%$ of respondents had no idea about the relationship. Table 2 depicts variables' distribution.

Table 2: Variables distributions

\begin{tabular}{|c|c|c|c|c|c|c|c|c|c|}
\hline Statistic & 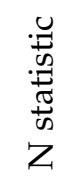 & 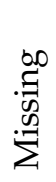 & $\stackrel{\varpi}{\Xi}^{\approx}$ & 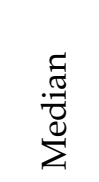 & $\frac{0}{8}$ & 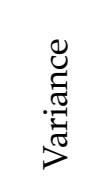 & 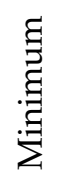 & 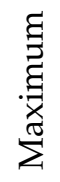 & 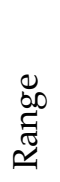 \\
\hline \multicolumn{10}{|l|}{ Variables } \\
\hline Adoption intention (AI) & 454 & 8 & 12.48 & 12.00 & 12.00 & 11.51 & 4 & 20 & 16 \\
\hline Attitudes toward solar panel & 462 & 0 & 18.03 & 19.00 & 19.00 & 13.16 & 5 & 25 & 20 \\
\hline Perceived ease of use (PEOU) & 462 & 0 & 13.15 & 13.00 & 12.00 & 8.28 & 5 & 20 & 15 \\
\hline Perceived usefulness (PU) & 454 & 8 & 15.56 & 16.00 & 16.00 & 5.75 & 7 & 20 & 13 \\
\hline Cost & 462 & 0 & 10.66 & 11.00 & 9.00 & 6.30 & 3 & 15 & 12 \\
\hline Knowledge & 462 & 0 & 6.43 & 6.00 & 6.00 & 2.93 & 2 & 10 & 8 \\
\hline Trust in developers & 462 & 0 & 9.65 & 9.00 & 9.00 & 5.84 & 3 & 15 & 12 \\
\hline
\end{tabular}

According to Table 2, the mean score of 12.48 for adoption intention in the range of 4 for the lowest intention to apply the technology and 20 for the highest intention demonstrates that respondents are located in the gray area of decision. In contrast, the attitude of people (mean score is 18.03) about the issue were reported higher. Regarding the perceived ease of use (PEOU) in the range of 5 and 20, the 13.15 score indicates respondents are dubious whether solar panels technology is an easy-usage technology for everyday life or not. In the case of perceived usefulness (PU), the mean score of respondents is 15.56 in the range of 7 to 20. It means that people consider solar panel technology as a useful one. One item of perceived usefulness construct was about clean air and all respondents $(100 \%)$ mentioned that using solar panel would help to have clean 
air. The mean score of 10.66 for the cost in the range of 3 to 15 demonstrates that the technology is an expensive one for end-users. 9.3\% that believed this is not an expensive technology for them, $49.4 \%$ has no idea about the price and $41.3 \%$ reported this as an expensive technology. In the case of knowledge, the mean score of 6.43 is located in the range of 2 to 10 . This score means respondents have a fairly good knowledge about the positive effects of solar panel usage on the environment but around half of them have no idea about these items.

\section{Results}

\subsection{Direct and Indirect Effects}

Two matrices in Tables 3 and 4 represent the correlation between the constructs of the research model, significance, direct, and indirect effects base on the research model. According to Table 3, the strongest significant direct correlation has occurred between PEOU and PU, PU and attitude, attitude and intention respectively.

Table 3: Standardized estimates, direct, and indirect effects of the model construct

\begin{tabular}{lcccc}
\hline Direct correlations & Direct effect & Indirect effect & Total effect & P-value \\
\hline Usefulness $\leftarrow$ Easiness & 0.982 & - & 0.982 & 0.000 \\
Usefulness $\leftarrow$ Knowledge & -0.004 & - & -0.004 & 0.657 \\
Usefulness $\leftarrow$ Cost & -0.003 & - & -0.002 & 0.772 \\
Attitude $\leftarrow$ Easiness & -0.306 & 0.681 & 0.375 & 0.137 \\
Attitude $\leftarrow$ Usefulness & 0.693 & - & 0.693 & 0.000 \\
Attitude $\leftarrow$ Knowledge & 0.151 & $-0.003^{*}$ & 0.149 & 0.000 \\
Attitude $\leftarrow$ Cost & 0.174 & -0.002 & 0.173 & 0.000 \\
Attitude $\leftarrow$ Trust & 0.315 & - & 0.315 & 0.000 \\
Intention $\leftarrow$ Attitude & 0.374 & - & 0.374 & 0.000 \\
\hline
\end{tabular}

${ }^{*}=$ non-significant

Table 4: Standardized indirect effect on adoption intention

\begin{tabular}{lccc}
\hline Indirect correlations & Indirect effect & Total & P-value \\
\hline Intention $\leftarrow$ Trust & 0.118 & 0.118 & 0.001 \\
Intention $\leftarrow$ Cost & 0.065 & 0.065 & 0.001 \\
Intention $\leftarrow$ Knowledge & 0.056 & 0.056 & 0.001 \\
Intention $\leftarrow$ Easiness & 0.140 & 0.140 & 0.001 \\
Intention $\leftarrow$ Usefulness & 0.260 & 0.260 & 0.039 \\
\hline
\end{tabular}

The indirect effects on the dependent variables are mentioned in Table 4. These indices show that all indirect effects on the adoption intention are statistically significant and the strongest indirect effect relates to PU on adoption intention through mediating attitude.

\subsection{Structural Model Assessment}

To determine whether the model fits the data or not, there are at least three fit indices. GFI, CFI, $\mathrm{X}^{2} / \mathrm{df}$, and RMSEA are some of the determining indices in model fit tests [47]. According to Amos, 
output model fit indices and $\mathrm{R}$ square of each dependent construct have been mentioned in Tables 5 and 6 , respectively.

Table 5: Model fit indices

\begin{tabular}{lcccc}
\hline Name of index & $\mathrm{X}^{2} / \mathrm{df}$ & GFI & CFI & RMSEA \\
\hline Index value & 0.462 & 0.95 & 1.00 & 0.000 \\
Level on acceptance & $\leq 2$ & $\geq 0.9$ & $\geq 0.9$ & $\leq 0.05$ \\
Current model & Optimal & Optimal & Optimal & Optimal \\
\hline
\end{tabular}

Table 6: Squared multiple correlations

\begin{tabular}{lc}
\hline & Estimate \\
\hline Usefulness & .965 \\
Attitude & .308 \\
Intention & .140 \\
\hline
\end{tabular}

Fit indices in Table 5 show the specified structural model fits the data acceptably. The indices indicate the designed model can be accepted to study attitudes and adoption intention. The result indicates independent variables of PEOU, PU, knowledge, cost, and trust explain $30 \%$ of the inhabitants' attitudes $\left(R^{2}=0.308\right)$. The main dependent variable is acceptance intention and results show the research model, overall explained $14 \%$ of the dependent variable. These results express that constructs are better predictors of attitude rather adoption intention.

\subsection{Results of hypotheses testing}

H1 is tested two-tail relationships between age, gender, income, education, and households' attitude toward solar panels. Results of one-way ANOVA for age ( $F=1.186$ and Sig $=0.315)$ and $\mathrm{t}$-test for gender $(\mathrm{t}=-1.427$, Sig $=0.154$ and mean difference $=-0.484)$ showed no significant correlation between individuals' age, gender, and attitude toward solar panel. The positive correlation between two other demographic factors of income $(\mathrm{F}=2.248$; Sig $=0.049$ and Mean S. $=29.384)$ and education $(\mathrm{F}=2.733$; Sig $=0.009$ and Mean $\mathrm{S} .=34.47)$ supported by data. These significant relationships mean that the more users are educated and rich, the more probable they have a positive attitude toward solar panel technology. Tables 7 shows the results of the main hypotheses test.

\section{Discussion}

Data analysis showed the research model explains around 31\% of the residents' positive attitudes toward solar panels and $14 \%$ of their adoption intention (see Table 6). Data also revealed that demographic variables of age and gender have no significant relationship with attitudes. This finding is similar to Paravantis et al. [24] that indicated no statistically significant relationship between age and positive willingness to pay for RE in Greece. However, there are different findings. For instance, Arega and Tadesse [47] reported a positive relationship between gender and attitude toward RE. They expressed that males are more likely to have a positive attitude toward RE. Two other demographic variables of income and education presented significant relationships among 
Journal of Asian Energy Studies (2021), Vol. 5, 42-57

Table 7: Results of hypotheses testing

\begin{tabular}{lcccc}
\hline & Hypothesized path & $\mathrm{t}$ & $\mathrm{Sig}$ & Remarks \\
\hline H2 & PU $\rightarrow$ Attitude & 7.196 & 0.000 & Supported \\
H3 & PEOU $\rightarrow$ Attitude & 1.763 & 0.224 & Not Supported \\
H4 & Cost of use $\rightarrow$ Attitude & 3.861 & 0.000 & Supported \\
H5 & Trust $\rightarrow$ Attitude & 7.111 & 0.000 & Supported \\
H6 & Knowledge $\rightarrow$ Attitude & 3.437 & 0.001 & Supported \\
H7 & PEOU $\rightarrow$ PU & 9.904 & 0.000 & Supported \\
H8 & Knowledge $\rightarrow$ PU & 5.116 & 0.000 & Supported \\
H9 & Cost of use $\rightarrow$ PU & 3.680 & 0.000 & Supported \\
H10 & Attitude $\rightarrow$ BI & 9.467 & 0.000 & Supported \\
\hline
\end{tabular}

studied people. This result is in line with Arega and Tadesse [48] that showed well-educated people have more positive attitude toward RE in comparison to the less-educated people and is in contrast with some previous studies, such as Mosly and Makki [49], Paravantis et al., [24] and Larijani et al. [50]. Results show that income and education have a positive significant impact on attitudes but the effectiveness is almost nothing. The bivariate correlation between education and income is almost $13 \%$ and $14 \%$, respectively. Given our results, demographical features of the respondents have no remarkable impact on their attitudes. One analysis, for this reason, could be the subject of the study. It is relatively a new subject in Iran, especially in rural areas. Although people are familiar with solar panels that the Ministry of Energy has installed in some administrative buildings, they do not have this technology in their own lives and due to its novelty for them, according to NIMBY ${ }^{3}$, they are not very interested to have the new technology in their own life. Therefore, it is predictable that different socio-demographic features have not made remarkable differences regarding the issue. Meeting energy requirements through clean energy technology has not converted into the Iranians' priority in rural areas yet. Given the financial situation of the rural residents, other issues such as a better job, more monthly income, equal life situation, more equitable distribution of life facilities and material welfare are given priority.

As hypothesized by $\mathrm{H} 2$, findings indicate PU has a positive significant effect on the inhabitants' attitudes on solar panel $(\mathrm{R}=0.693, \mathrm{Sig}=0.000)$. Previous results of Davis , Chen et al. [52], and Hwang [53] support this result and Kardooni et al. [36] indicated PU has a significant role in the acceptance of new technology. In the case of $\mathrm{H} 3$, findings declare that the assumed relationship between perceived ease of use (PEOU) and attitudes is not supported by data. This result is in contrast with the results of Davis [50], Kardooni et al. [36], and Tsaur and Lin [33] who claimed PEOU is a determinant factor in new energy acceptance among new users. While there is no direct impact of PEOU on attitude, we found an indirect effect through PU. The results of $\mathrm{H} 2$ and H3 indicate how PU is a strong determinant to shape a positive attitude toward solar panels among people.

H4 assumed solar panel technology cost should have a negative effect on attitudes. Usually, the high cost of the pro-environmental lifestyle is considered an inhibitor factor in environmental protective behaviors. H4 reported a positive correlation $(R=0.174$ and Sig $=0.000)$. Data doesn't support the hypothesis. This result needs more investigation in future research to understand why in a community where people suffer from financial deficiencies, the high cost of solar panel installation does not result in a negative impact on individuals' attitudes. Two potential

${ }^{3}$ Not In My Back Yard 
explanations can be deduced from the research. First, the attitude was measured by five items that were about the role of government financial incentives and subsidies in solar panels expanding. $51 \%$ had positive attitudes towards solar panel development provided there was government financial support. Therefore, in this situation, as long as the cost is met by subsidies, might not have a significant impact on attitude. Second, with the current economic situation in Iran where the annual inflation rate jumped to beyond $40 \%$ in the last months of $2018^{4}$ (Central Bank of Iran $2018^{5}$ ), people are trying to mitigate their living costs and hence, changing household energy sources from conventional to solar is not their urgent concern and therefore, cost would not be decisive in their decision. Overall, either the items were not appropriate for measuring the correlation, or individuals did not care about the cost as they have no intention to implement the new technology; further investigation is needed.

H5 measured the relationship between trust in developers and individuals' attitudes toward the development of solar panels. Multiple regression results $(R=0.315$ and $\mathrm{Sig}=0.000)$ supported the hypothesis. The more trust people have in developers (distributors, advertisers and sellers), the more positive attitudes they might have about solar panel development. This result is in line with the findings of Liu et al. [21] and Steg et al. [37]. The result indicates that more than 59\% of respondents are not trustworthy in developers of solar panels systems. Therefore, if energy transition is an up-bottom project and the Iranian government has planned to increase the part of clean energy generation, they should seriously consider the trust restoration in society.

The relationship between climate knowledge and attitudes was assessed in H6. Regression results for the direct effect of knowledge on attitude $(R=0.294$, Sig $=0.000)$ supported the hypothesis. People who have more knowledge about climate change [53] and energy resources [33] are more concerned about natural problems, have more positive attitudes toward protective behaviors, and accept solar panels easier. The finding was also supported by Komendatava et al. [4] and Molin [54].

Hypotheses 7, 8, and 9 assumed that PEOU, knowledge, and cost might have an impact on attitude and adoption intention indirectly through PU. Regression result supported these hypotheses (Beta PEOU $=0.408, \mathrm{~B}_{\text {knowledge }}=0.149$ and $\mathrm{B}_{\text {cost }}=0.211$ and Sig $\left.=0.000\right)$. H10 was related to the possibility of the positive impact of attitude on adoption intention. Results $(R=0.400$ and Sig $=0.000)$ confirm that the hypothesis is in line with the theory of planned behavior [55] and the findings of Korcaj et al. [31] examined the role of attitude on behavioral intention.

\section{CONCLUSION}

To achieve a relatively sustainable social and environmental development, Iran needs to develop REs share in its energy market. When it comes to internal policymaking and international commitment, the Iranian government policies apparently covers the concerns. Politicians pass various deals in parliament and write periodically Five Years National Development Plans by taking into consideration necessary actions to protect nature more, reduce conventional energy consumption, increase the amount of REs share in the power generation mix, allocate subsidies for renovating and rebuilding old infrastructures, and develop the role of solar panels in domestic energy consumption (Sixth Five Year National Development Plan 2016). Regardless of these policies, Iran is still one of the 10 largest producers of GHG in the world. In recent years, the government through implementing some interim policies, such as cutting conventional fuels subsidies and increasing energy cost as well as allocating subsidies for solar panel installation has tried to encourage people to shift their energy resources from conventional to renewables. By

\footnotetext{
${ }^{4}$ Several months before data collection

${ }^{5}$ For more information see: https://tradingeconomics.com/iran/inflation-cpi
} 
strengthening these actions, in 2016 TAVANIR $^{6}$ estimated that, in the next five years, $10 \%$ of the country's energy need would be met by REs [55]. However, in practice, only a small part of this prediction has been actualized so far. Achieving these targets through energy transition is not an easy way forward going for the government or for household users. It is costly, effortful, and less pleasurable [37], and a combination of rules and regulations, pricing policies, social incentives, and technological innovations are required to apply [56]. Literature reveals that this kind of transition usually occurs in countries that have already passed some environmental-protective policies and regulations.

Part of the successful implementation of transition projects in any country depends on social and institutional trust and it is necessary to be considered in the Iranian context as well. People object to the lack of efficient environmental policies that cannot preserve nature and believe applying solar panel technology to meet household needs could not be a good initial step to move forward into sustainability. In the social adoption of new technologies, cooperation between government, industry and civil society provides a favorable social context to approach sustainable objectives [57]. In other words, in moving toward sustainability through the energy transition, several basic prerequisites, such as social, cultural, political, economic, institutional, and technological factors are required at the local and national levels.

First and foremost, we need sustainable regulations that address not just energy sectors but public policies and their positive consequences are touchable in the social sphere. In developing countries, people do not believe that policies are made to protect their rights, society, and their environment; mere speeches to act like a responsible consumer will not be fruitful. Steg et al. [57] consider policy and system changes as a significant factor influencing sustainable energy behavior and Sovacool [58] emphasizes perceived fairness, equity, and justice in creating more humanized energy consumption behavior. Also, executive law and regulations should support the policies. In the studied context, people understand that many parliamentary passed articles either are not in favor of nature or if they are, they don't implement in practice. In his recent research, Solaymani [59] revealed that the absence of suitable and effective government policies mainly negatively restricts the development of REs. We already know that the more people feel alienated from applied policies, the more they resist their implementation [21,60]. Lack of this factor in the studied society broadly discourages individuals to trust in such policies to implement and therefore, they prefer to continue with the existing old-fashioned methods.

Moreover, in addition to efficient government, political, and socio-structural factors as well as updated substructures, Iranian society needs more aware and concerned citizens. A systematic education program that socializes citizens from schools to universities in a way that how much nature protection is both vital per se and necessary for their wellbeing and how much citizens are responsible for this. This is an efficient method to bring up active, sustainable, and responsible citizen-consumers. A reliable and responsible structure and governance can reach this purpose. In addition to the aforementioned factors, there is a broad range of other economic, technological, political, and social factors that directly and indirectly influence solar energy adoption among Iranians and especially in rural areas. This research addressed the question from a sociological perspective to provide a slightly clear picture in comparison to the previous studies.

Keeping this in mind, a suggestion for future research is to attempt to design a better research model, which includes more compatible constructs with the target society and choose a more relevant sample. Data revealed that the target society was not enough mentally developed to address the research question. In a society where there is no tangible sustainable consumption culture [10], and due to its various managerial deficiencies [59], short-term decisions have priority to long-term objectives. Therefore, inviting villagers that suffer from plenty of challenges in their

${ }^{6}$ Iran Power Generation, Transmission and Distribution Management 
everyday life to embrace such costly and leading technology seems inappropriate. Furthermore, selecting the participants who had not yet installed solar panels at the study time and were not familiar with the functions of the new system to respond to our questionnaire was not enough fitted to the objective of the research. Therefore, there is a probability that PU and PEOU couldn't estimate the correlations between model variables. Selecting more appropriate samples and more accurate constructs would be two critical factors that should be taken into consideration for future research. This study revealed the factors that should be considered in future studies of the development of social adoption of solar technology in developing countries that are confronted with the consequences of their unsustainable development and try to find a solution to mitigate their negative impacts.

Acknowledgement: We would like to thank sociology master students of the University of Mazandaran who helped us collected data from hard-to-reach villages of the region.

Funding: This work was financially supported by Iran National Science Foundation (INSF), (grant number 97023254, 2019).

Availability of data and material: Datasets related to this article can be found at http://doi.org/ 10.17632/tksp7ms69r.1, an open-source online data repository hosted at Mendeley Data.

\section{Declaration of interest: None}

\section{REFERENCES}

[1] Ministry of Energy of Iran. 2020. Available at: https://www.tehrantimes.com/news/455848/ Iran-has-great-capacities-to-expand-renewable energy-market

[2] Rezaee MJ, Yousefi S, Hayati J. Root barriers management in development of renewable energy resources in Iran: An interpretative structural modeling approach. Energy Policy 2019:129:292-306.

[3] Nejat P, Morsoni AK, Jomehzadeh F, Behzad H, Vesali MS, Majid MZA. Iran's achievements in renewable energy during fourth development program in comparison with global trend. Renewable and Sustainable Energy Reviews 2013:22:561-570.

[4] Komendantava N, Yazdanpanah M, Aredestani R. Studying young people' views on deployment of renewable energy sources in Iran through the lenses of Social Cognitive Theory. AIMS Energy 2018:6:216-229.

[5] Afsharzade N, Papzan A, Ashjaee M, Delangizan D, Van Passel S, Azadi, H. Renewable energy development in rural areas of Iran. Renewable and Sustainable Energy Reviews 2016:65:743-755.

[6] Hemmati M. A sustainable transition to renewable energy resources in oil producing countries: A case study of Iran. Master Thesis in Innovation and Spatial Dynamics. Lund University. Sweden, 2017

[7] Quentin M. Opportunities for alternative energies depolyment in Iran. Sciences Po 2020. https://www.sciencespo.fr/kuwait-program/wp-content/uploads/2021/02/QuentinMINIER-Opportunities-for-alternative-energies-deployment-in-Iran.pdf.

[8] Aien M, Mahdavi O. On the way of policy making to reduce the reliance of fossil fuels: Case study of Iran. Sustainability 2020:12:10606.

[9] Iran Renewable Energy Organization. Website: http://www.suna.org.ir/home-en.html 
[10] Karimzadeh S, Salehi S. A study of households' intention towards solar panel installation case study: Villagers of the northern regions of Iran. Environmental Sociology 2021:7:434-446.

[11] Rezaei R, Ghofranfarid M. Rural households' renewable energy usage intention in Iran: Extending the unified theory of acceptance and use of technology. Renewable Energy 2018:122:382-391.

[12] Ardehali M. Rural energy development in Iran: Nonrenewable and renewable Resources. Renewable Energy 2006:31:655-662.

[13] Ghofranfarid M, Rezaei R. Affecting factors on using of renewable energies in rural areas of Zabol City. Journal Of Environmental Education and Sustainable Development 2017:5:35-48.

[14] Yazdanpanah M, Komendantova N, Ardestani R. Governance of energy transition in Iran: Investigating public acceptance and willingness to use renewable energy sources through socio-psychological model. Renewable and Sustainable Energy Reviews 2015:45:565-573.

[15] Shobeiri M, Bayati M. Study of social acceptance of solar energy systems from the viewpoints of people in Arak city. Fifth Conference on Clean, Efficient and Renewable Energy, Tehran, 2014.

[16] Shadi Talab J, Nayehder M. Analyzing the factors influencing adoption of solar water heaters in rural areas (Case study: Bardaskan county). Journal of Rural Development 2009:1:67-87.

[17] Horta A. Energy consumption as part of social practices the alternative approach of practice theory, In: Davidson DJ, and Gross M (ed.). Energy and Society. Oxford University Press, Oxford, 2018.

[18] Wustenhagen R, Maarten W, Burer M. Social acceptance of renewable energy innovation: An introduction to the concept. Energy Policy 2007:35:2683-2691.

[19] Mallett A. Social acceptance of renewable energy innovations: The role of technology cooperation in urban Mexico. Energy Policy 2007:35:2790-2798.

[20] Stephenson JR, Sovacool BK, Inderberg THJ. Energy cultures and national decarbonisation pathways. Renewable and Sustainable Energy Reviews 2021:137:110592.

[21] Liu L, Thijs B, Perlaviciute G, Steg L. Effects of trust and public participation on acceptability of renewable energy projects in the Netherlands and China. Energy Research E Social Science 2019:53:137-144.

[22] Sauter R, Watson J. Strategies for the deployment of micro-generation: Implications for social acceptance. Energy Policy 2007:35:2770-2779.

[23] Jobert A, Laborgne P, Mimler S. Local acceptance of wind energy: Factors of success identified in French and German case studies. Energy Policy 2007:35:2751-2760.

[24] Paravantis JA, Stigka E, Mihalakakou G, Michalena E, Hills J, Dourmas V. Social acceptance of renewable energy projects: A contingent valuation investigation in Western Greece. Renewable Energy 2018:123:639-651.

[25] Tsoutsos TD, Staltiboulis A. The Sustainable Diffusion of Renewable Energy Technologies as an Example of an Innovation-focused Policy. Technovation 2005:25:753-761.

[26] Harmon RR, Cowan KR. A multiple perspectives view of the market case for green energy. Technological Forecasting and Social Change 2009:76:204-213.

[27] Panoutsou, C. Bioenergy in Greece: Policies, diffusion framework and stakeholder interactions. Energy Policy 2008:36:3674-3685.

[28] Palm A. Peer effects in residential solar photovoltaics adoption-A mixed methods study of Swedish Users. Energy Research \& Social Science 2017:26:1-10.

[29] Mirza UK, Ahmad N, Harij K, Majeed T. Identifying and addressing barriers to renewable energy development in Pakistan. Renewable and Sustainable Energy Reviews 2009:13:927-931.

[30] Nalan ÇB, Murat Ö, Nuri Ö. Renewable energy market conditions and barriers in Turkey. Renewable and Sustainable Energy Reviews 2009:13:1428-1436. 
[31] Korcaj L, Hahnel UJJ, Spada HH. Intentions to adopt photovoltaic system depend on hometown expected personal gains and behavior of peers. Renewable Energy 2015:75:407-415.

[32] Davis FD, Bagozzi RP, Warshaw PR. User acceptance of computer technology: a comparison of two theoretical models. Management Science 1989:35:982-1003.

[33] Tsaur RC, Lin YH. Exploring the consumer attitude of building-attached photovoltaic equipment using revised technology acceptance model. Sustainability 2018:10:4177.

[34] Venkatesh V, Davis F. A theoretical extension of the technology acceptance model: Four longitudinal field studies. Management Science 2000:46:186-204 .

[35] Müller JM. Comparing technology acceptance for autonomous vehicles, battery electric vehicles, and car sharing - A study across Europe, China, and North America. Sustainability 2019:11:4333.

[36] Kardooni R, Yusoff SB, Kari FB. Renewable energy technology acceptance in Peninsular Malaysia. Energy Policy 2016:88:1-10.

[37] Steg L, Perlaviciute G, van der Werff E. Understanding the human dimensions of a sustainable energy transition. Frontiers in Psychology 2015:17805.

[38] Wolsink M. Undesired reinforcement of harmful self-evident truths concerning the implementation of wind power. Energy Policy 2012:48:83-87.

[39] Stern P, Thomas D. A broader social science research agenda on sustainability: Nongovernmental influences on climate footprints. Energy Research E Social Science 2020:60:101401.

[40] Siegrist, M. A causal model explaining the perception and acceptance of gene technology. Journal of Applied Social Psychology 1999:29:2093-2106.

[41] Kim H, Park E, Kwon SJ, Ohm JY, Chang HJ. An integrated adoption model of solar energy technologies in South Korea. Renewable Energy 2014:66:523-531.

[42] Halder P, Havu-Nuutinen S, Pietarinen J, Pelkonen P. Bioenergy and youth: Analyzing the role of school, home, and media from the future policy perspectives. Applied Energy 2011:88:1233-1240.

[43] Alasti E. Social Acceptance of bioenergy in Europe. Master Thesis in Environmental Management and Policy, Lund University, Sweden, 2011.

[44] Morgil I, Secke N, Yucel AS, Oskay OO, Yavuz S, Ural E. Developing a renewable energy knowledge scale for pre-service chemistry teachers. Turkish Online Journal of Distance Education 2006:7:63-74.

[45] Simpson G. Analyzing social acceptance of renewable energy policy in Australia: Community, industry and government perceptions of residential solar energy. Ph.D Thesis in School of Earth and Environment, Human Geography, University of West Australia, Australia, 2017.

[46] Carmines EG, Zeller R. Reliability and Validity Assessment. Sage, Thousand Oaks, 1979.

[47] Hair JF, Black WC, Babin BJ, Anderson RE. Multivariate Data Analysis: A Global Perspective. Pearson Education, London, 2010.

[48] Arega T, Tewodors T. Household willingness to pay for green electricity in urban and peri-urban Tigray, northern Ethiopia: determinants and welfare effects. Energy Policy 2017:100:292-300.

[49] Mosly I, Makki A. Current status and willingness to adopt renewable energy technologies in Saudi Arabia. Sustainability 2018:10:4269.

[50] Larijani M, Shobeiri M, Abolhasani E. Study of relationship between social acceptance of solar energy systems and the factors influencing it (Case study: Tabriz city). Iran Energy Journal 2014:17:1-14.

[51] Davis FD. Technology acceptance model for empirically testing new end-user information system: Theory and results. PhD Thesis, Massachusetts Institute of Technology, US, 1986. 
[52] Chen L, Gillenson M, Sherrell D. Enticing online consumers: an extended technology acceptance perspective. Information \& Management 2020:39:705-719.

[53] Hwang CG. Consumers' acceptance of wearable technology: Examining solar-powered clothing. Master Thesis, Iowa State University, US, 2014.

[54] Molin E. Causal analysis of hydrogen acceptance. Journal of the Transportation Research Board 2005:1941:115-121.

[55] Ajzen I. The theory of planned behavior. Organizational Behavior and Human Decision Processes 1990:50:179-211.

[56] IPCC. Global warming of $1.5^{\circ} \mathrm{C}$. An IPCC Special Report on the impacts of global warming of $1.5^{\circ} \mathrm{C}$ above pre-industrial levels and related global greenhouse gas emission pathways, in the context of strengthening the global response to the threat of climate change, sustainable development, and efforts to eradicate poverty.

[57] Steg L, Perlaviciute G, Sovacool B, Bonaiuto M, Diekmann A, et al. A Research agenda to better understand the human dimensions of energy transitions. Frontiers in Psychology 2021:12:2421.

[58] Sovacool BK. Who are the victims of low-carbon transitions? Towards a political ecology of climate change mitigation. Energy Research \& Social Science 2021:73:101916.

[59] Solaymani S. Review on Energy and Renewable Energy Policies in Iran. Sustainability 2021:13:7328.

[60] Gross C. Community perspectives of wind energy in Australia: The application of a justice and community fairness framework to increase social acceptance. Energy Policy 2007:35:2727-2736

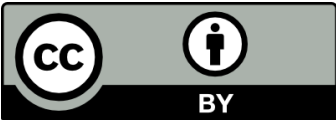

(C) The Author(s) 2021. This article is published under a Creative Commons Attribution (CC-BY) 4.0 International License. 